\title{
Structure and preferred orientation of primary phases of Ni-Al-Co-based alloy alloyed by Rhenium after annealing and creep exposure
}

\author{
Elena Nikonenko ${ }^{1,2, *}$, Natalya Popova ${ }^{1,3}$, Alisa Nikonenko $^{4}$, and Nina Koneva ${ }^{1}$ \\ ${ }^{1}$ Tomsk State University of Architecture and Building, 634003 Tomsk, Russia \\ ${ }^{2}$ National Research Tomsk Polytechnic University, 634050 Tomsk, Russia \\ ${ }^{3}$ Institute of Strength Physics and Material Science SB RAS, 634021 Tomsk, Russia \\ ${ }^{4}$ National Research Tomsk State University, 634050 Tomsk, Russia
}

\begin{abstract}
The present paper investigates phase composition and fine structure of Ni-Al-Co-based alloy alloyed by Rhenium (Re) ( 3 at.\%), as well as studies preferred orientation of the given alloy primary phases by means of scanning electron microscopy and X-ray diffraction analysis. The original state was given as the alloy which underwent a complete cycle of heat treatment: stepwise homogenization, cooling, annealing, and cooling at $100^{\circ} \mathrm{C} / \mathrm{min}$ back to room temperature. The alloy was further subject to annealing at $1000^{\circ} \mathrm{C}$ for $105 \mathrm{~h}$ and $968 \mathrm{~h}$. It was also exposed to creep experiments at the same temperature for $105 \mathrm{~h}$ (loading $320 \mathrm{MPa}$ ), and for $968 \mathrm{~h}(220 \mathrm{MPa}) \cdot \gamma$ - and $\gamma^{\prime}$-phases were established to be the primary phases in both states of face-centered cubic crystal lattice. $\gamma^{\prime}$-phase (phase with ordered atom arrangement having $\mathrm{L}_{2}$ superstructure) was the primary phase in all states of the alloy. Investigations showed that Re being able not to dissolve in the primary phases served as a phase-forming element. Phase composition and phase morphology were studied. The influence of high-temperature annealing and creep on superalloy structure and morphology of $\gamma^{\prime}$-phase were defined. The influence of creep on the structure was proven to be different from the annealing effect. First, creep generated larger dissipation of orientations than annealing. Second, anisotropy of $\gamma^{\prime}$-phase cuboids could be observed at meso-level. Cuboids partially joined together. Third, spheroidized cuboids could be often met after creep.
\end{abstract}

\section{Introduction}

Development and application of metallic materials to a large extend define advance in modern engineering due to their required operation properties. However the requirement levels applied to these materials constantly grow along with the new objectives engineers are facing while new equipment development, and its operation under extreme conditions in particular - high speeds, high temperatures, etc. Scientists are being in the constant search for metallic materials being able to withstand these extreme conditions. Thus, development

*Corresponding author: vilatomsk@mail.ru 
of alloys comprising intermetallic phases is considered as one of the promising research directions. Superalloys based on $\left(\gamma+\gamma^{\prime}\right)$-phases can serve as an example, where $\gamma$-phase is a disordered face-centered cubic (fcc) solid solution, while $\gamma^{\prime}$-phase is an ordered phase with $\mathrm{L1}_{2}$ superstructure [1-3]. $\gamma^{\prime}$-phase is the primary phase in these modern superalloys. This is the reason why $\gamma^{\prime}$-phase is largely responsible for the formation of superalloy properties. Currently, superalloys are often produced based on the $\mathrm{Ni}-\mathrm{Al}$ alloy [1], alloyed by various refractory elements $[1,3,4]$. However, introduction of large amount of different alloying elements as well as annealing and creep of superalloy can change its texture [5]. The present paper investigates the issues mentioned above.

\section{Materials and methods}

Material of study was a complex metallic alloy. The basic elements of the alloy were $\mathrm{Ni}$ from 69 to 59 at.\%, $\mathrm{Al}$ from 12 to 15 at.\% and Co from 10 to 13 at.\%. Cr, Ta and Re were used as alloying elements in the amount no more than 3.5 at.\% of each, and also $\mathrm{W}$ and Mo in smaller amounts.

The structure of the alloy was investigated within the following alloy states: 1) original state (after directional crystallization); 2) after $1000^{\circ} \mathrm{C}$ annealing for $105 \mathrm{~h} ; 3$ ) after $1000^{\circ} \mathrm{C}$ annealing for $968 \mathrm{~h}$; 4) after creep tests at $1000^{\circ} \mathrm{C}$ for $105 \mathrm{~h}$ and load $320 \mathrm{MPa}$; and 5) the state while creep tests $968 \mathrm{~h}$ under load $220 \mathrm{MPa}$ and temperature $1000^{\circ} \mathrm{C}$.

X-ray diffraction analysis (XRD) on thin foils using EM-125 transmission electron microscope with $125 \mathrm{kV}$ accelerating voltage was used as the main research method. The specimens for investigating structure were cut perpendicularly to the axis of crystal growth [001]. According to microdiffraction images obtained from electron microscope, phase composition of the alloy was defined for all states, also the morphological types of $\gamma^{\prime}$-phase cuboids and appearing stereographic components in the alloy. Orientations distribution considering their "specific mass" was placed on a standard stereographic triangle, the orientations were analyzed.

\section{Results and discussion}

\subsection{Phase composition and $\gamma^{\prime}$-phase state}

Electron microscopy investigations have shown a combination of a number of phases in different states of the alloy the qualitative and quantitative composition of which depends on the state (Table 1).

Table 1. Phase composition and volume fractions of the primary phases in the specimens under study.

\begin{tabular}{|c|c|c|c|}
\hline \multirow{2}{*}{$\begin{array}{c}\text { No. } \\
\text { specimen }\end{array}$} & \multicolumn{2}{|c|}{$\begin{array}{c}\text { Primary phases, } \% \\
( \pm \mathbf{1 \%})\end{array}$} & \multirow{2}{*}{ Secondary phases } \\
\cline { 2 - 3 } & $\boldsymbol{\gamma}^{\prime}$-phase, & $\boldsymbol{\gamma}$-phase, & \\
\hline 1 & 80.0 & 19.7 & $\chi$-phase \\
\hline 2 & 78.0 & 21.5 & Laves phase, $\sigma$-phase \\
\hline 3 & 66.0 & 33.8 & Laves phase, $\sigma$-phase \\
\hline 4 & 79.0 & 20.7 & Laves phase, $\sigma$-phase \\
\hline 5 & 58.0 & 41.9 & Laves phase \\
\hline
\end{tabular}


Phases observed in the superalloy can be classified into primary and secondary. This classification is based on volume fraction of phases, their contribution to and constant or single presence in the alloy. As can be seen from Table $1, \gamma^{\prime}$ - and $\gamma$-phases are the primary. As a rule, they form the primary structure of alloy in almost all of the superalloys [1-4]. They can be found in the alloy under study as $\gamma^{\prime}$-phase quasi-cuboids separated by interlayers of $\gamma$-phase. Other phases are secondary [6,7]. Different state of the alloy is marked by different secondary phases [6,7]. Volume fractions of the primary phases present in different states of the alloy are also given in Table 1. As can be seen from Table 1, volume fraction of $\gamma^{\prime}$ - phase is kept high in all states of the alloy. It represents cuboids, more often with quite distinct cutting. Their sizes and shape depend on the parameters of heat treatment and creep.

Microphotographs in Figure 1 obtained by XRD show that $\gamma^{\prime}$-phase cuboids can be classified into several types according to their morphology, given as follows:
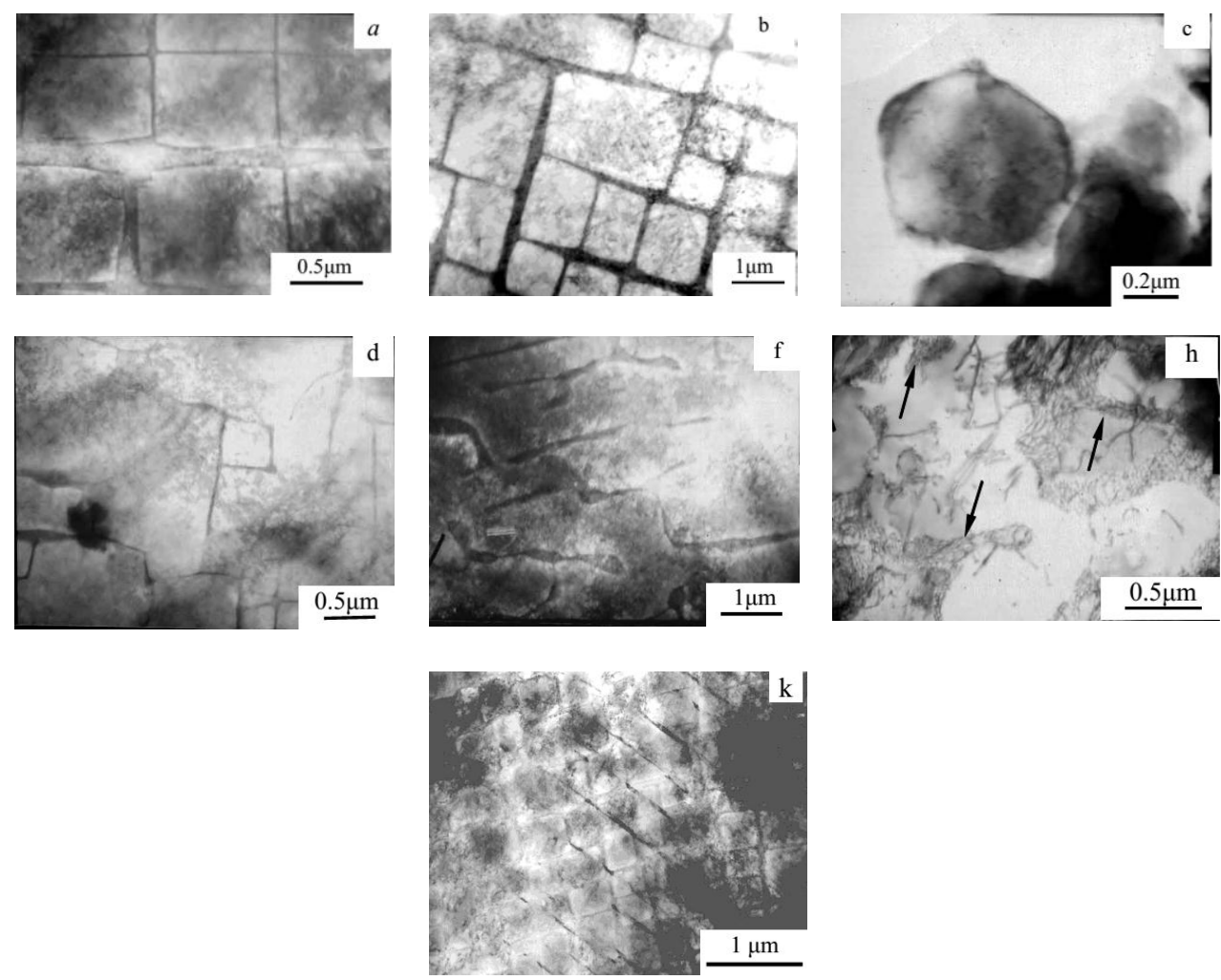

Fig. 1. Morphological types of $\gamma^{\prime}$-phase cuboids: a - homogeneous; $\mathrm{b}$ - non-homogeneous; $\mathrm{c}-$ spheroidized; $\mathrm{d}$ - with damaged structure; $\mathrm{f}$ - destructed; $\mathrm{h}$ - constrained by dislocation walls; $\mathrm{k}$ with second cuboid orientation.

$>$ Homogeneous cuboids (Fig. 1a) are cuboids which are almost of the same size, i.e. dispersion comprises the value of not more than $0.005 \mu \mathrm{m}$.

$>$ Non-homogeneous cuboids (Fig. 1b). The size of cuboids differs significantly from each other. Dispersion of the size in areas of material which contain such cuboids comprises the value which is $>0.2 \mu \mathrm{m}$.

$>$ Spheroidized cuboids (Fig. 1c) are cuboids of a round shape. They are indicative of the alloy after creep. 
Cuboids with damaged structure. Examples of such cuboids are given in Figure 1d. As it is seen from the given microphotographs structural damage can be defined as presence of cut boundary inside the cuboid or irregular shape of the cuboid, when the cuboid lacks one or more walls. Such cuboids can be found in all alloys studied in the present paper.

$>$ Destructed cuboids (Fig. 1f). These areas of structure are marked by only separate walls of cuboids left.

$>$ Local location of $\gamma^{\prime}$-phase (Fig. 1h) is when $\gamma^{\prime}$ cuboids are constrained by dislocation walls.

$>$ Presence of second cuboid orientation. These are lamellar precipitate (according to packet types of thin long twins) being present in separate locations of structure. In regards to $\gamma^{\prime}$-phase cuboids they are generally located within the direction $<110>$, or $<001>$ (Fig. 1k).

Damage of $\gamma^{\prime}$-phase cubic structure under creep conditions is apparently connected with the formation of dislocation structure [3,8].

$\gamma$-phase being one of the primary phases is given as relatively thin interlayers placed between the $\gamma^{\prime}$-phase cuboids. It can be found in all states of the alloy.

\subsection{Preferred orientation of $\gamma$ - and $\gamma^{\prime}$-phases}

Alloys like $\left(\gamma+\gamma^{\prime}\right)$ are generally characterized by complete orientation correspondence between $\gamma$ - and $\gamma^{\prime}$-phases [3,9-12]. Some similar phenomenon took place in the alloy under study, mainly in those states where the structure of cuboids was somehow damaged due to directional crystallization by means of which the specimens under study were obtained. In this case well-ordered texture [001] should be developed. In order to investigate that, specimens were cut perpendicularly to the growth axis, then tin foils were made from them and appearing stereographic components were studied. Distribution of orientations was studied considering their specific mass. The key data is presented in Figure. 2.

Compared with specimens having lower Re content which were studied before $[3,8]$ a significant dispersion of crystal orientation was observed. In the states after annealing the fraction [001] was less than 0.1. It should be noted that in the original and annealed samples cubic orientation of $\gamma$ - and $\gamma^{\prime}$-phases were not well distinct. Creep test increased the fraction of cubic orientation by 2-5 times. In this case dissipation was significantly eliminated along the angle bisector [001]. It is especially well seen in specimen No. 5. Decrease of diagonal components of texture increased the role of components lying along the triangle side [001] $-[011]$. 

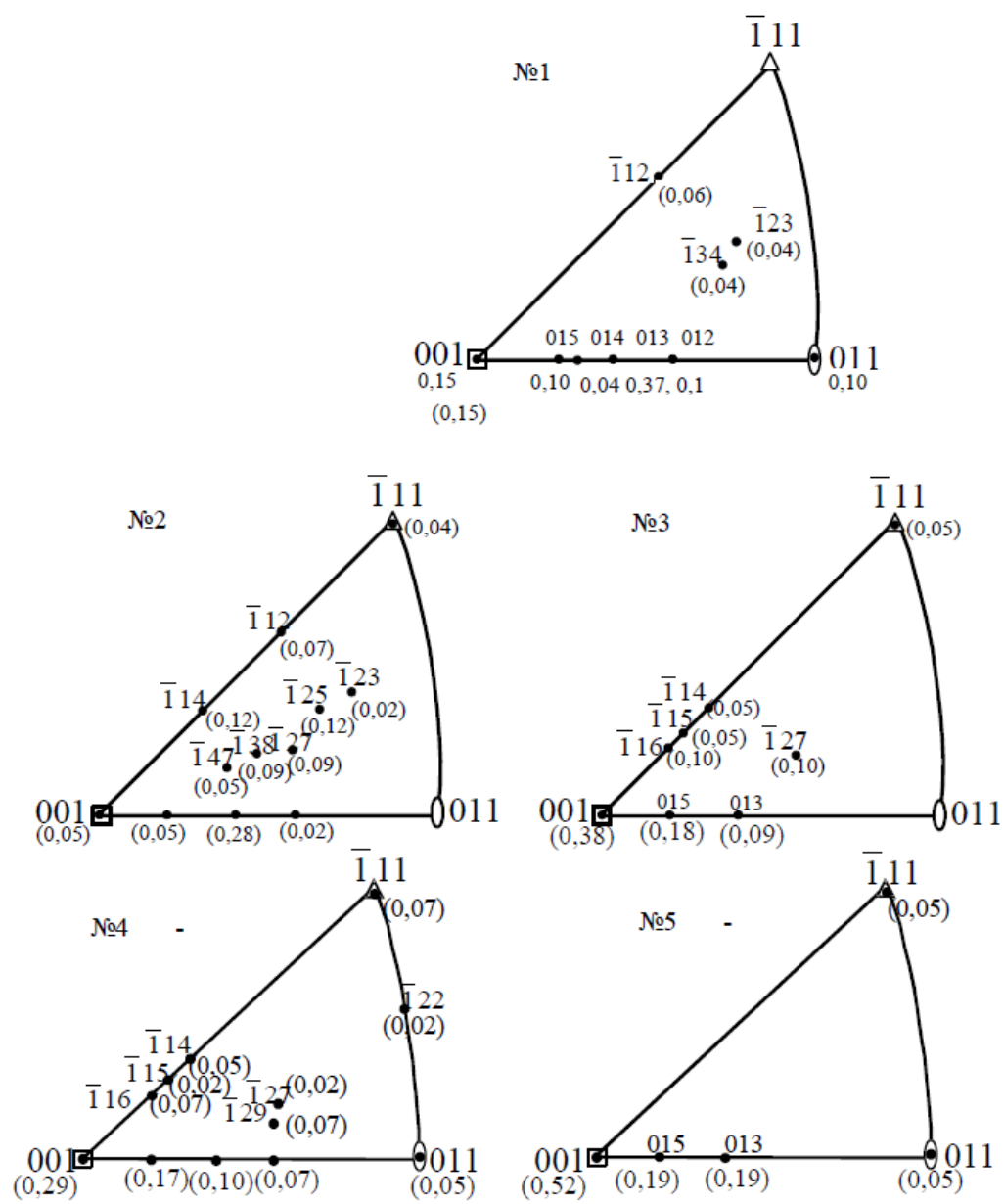

Fig. 2. Distribution of orientations considering their specific mass in the alloy.

\section{Conclusion}

Resulting from conducted studies it was found that under creep conditions dislocation structure was formed the way that cubic structure was damaged and preferred orientation was changed. The other mechanism of orientation change was diffusive creep mechanism leading to cuboid structure damage at macro level. Cuboid shape turned into round one. The given works highlight the importance of both dislocation and diffusive creep mechanisms.

\section{References}

1. N.S. Stoloff, C.T. Sims, W.C. Hagel, Superalloys II High-Temperature Materials for Aerospace and Industrial Power (John Wiley \& Sons, New York,1987)

2. R.C. Reed, The Superalloys: Fundamentals and Applications (University Press, Cambridge, 2006)

3. Yu.R. Kolobov, E.N. Kablov, E.V. Kozlov, Struktura i svoistva intermetallidnykh 
materialov s nanofaznym uprochneniem [Structure and properties of intermetallic materials with nanophased hardening] (MISiS Publ., Moscow, 2008) (in Russian)

4. R.C. Reed, T. Tao, N. Warnken, Act. Mat., 57, 5898 (2009)

5. P. Caron, T. Khan, TMS Fall Meeting (IN, TMS, Indianapolis, 2001)

6. E.L. Nikonenko, N.A. Popova, T.V. Dement, N.A. Koneva, Rus. Phys. J. 60, 231 (2017)

7. E.V. Kozlov, A.N. Smirnov, E.L. Nikonenko, N.A. Popova, N.A. Koneva, Morfologiya faz i fazovye prevrashcheniya pri termicheskoi obrabotke supersplavov na osnove Ni-Al-Cr i Ni-Al-Co. Masshtabnye i kontsentratsionnye effekty [Phase Morphology and Transformations at Thermal Treatment of Ni-Al-Cr- and Ni-Al-Cobased Superalloys. Scale and Concentration Effects] (Innovatsionnoe mashinostroenie, Moscow, 2016) (in Russian)

8. C.M.F. Rae, R.C. Reed, Acta Mater. 49, 4113 (2001)

9. E.V. Kozlov, E.L. Nikonenko, N.A. Popova, N.A. Koneva, Bul. Rus. Ac. Sci. Phys. $78,4,267$ (2014)

10. J.T. Guo, L.Y. Sheng, Y. Xie, Z.X. Zhang, V.E. Ovcharenko, H.Q. Ye, Intermetallics, 19, 2, 137 (2011)

11. Y. Yu, J. Zhou, J. Chen, H. Zhou, C. Guo, B. Guo, Intermetallics, 18, 5, 871 (2010)

12. E.N. Kablov, V.N. Tolorajja, I.M. Demonis, N.G.Orehov, Tehnol. leg. spl., 2, 60 (2007) 